\title{
Acromegaly in Iraq: Brief look on epidemiology, comorbidities and management
}

\author{
Berq J. Hadi Al-Yasseri,a* Abbas M. Rahmah, and Nizar S. Shawky Al-Saffar ${ }^{b}$
}

\author{
aCollege of Medicine, Al-Nahrain University, Baghdad, Iraq. \\ 'National Diabetes Center, Mustansiriyah University, Baghdad, Iraq. \\ "Correspondence to Berq J. Hadi Al-Yasseri (email: dr_berq@yahoo.com). \\ (Submitted: 15 October 2018 - Revised version received: 06 November 2018 - Accepted: 25 December 2018 - Published online: 26 June 2019)
}

\begin{abstract}
Objective Acromegaly is a rare chronic condition in adults resulted from continuous over secretion of growth hormone (GH) and hence increased production of insulin-like growth factor-1 (IGF-1). Pituitary adenoma is the underlying cause in vast majority of cases. This study aims to evaluate clinico-epidemiological characteristics for a group of Iraqi individuals with this disease.

Methods Case notes and files of 60 acromegalic patients attending Iraqi National Diabetes Center were reviewed during period of October through December 2017. To be included, the diagnosis of acromegaly should be confirmed by appropriate laboratory and imagining techniques. Disease control and biochemical response to management was defined by the criteria of normalized IGF-1 for age and sex (Z-score $\leq 2$ ) and a mean $\mathrm{GH}$ value of $\leq 2 \mu \mathrm{g} / \mathrm{l}$. Data was entered and analyzed using statistical package for social sciences program, version 20. Descriptive statistics was used; presented as frequencies and proportions, or means and standard deviations according to variable type. Results Patients were almost equally distributed among both sexes. Their mean age is $50.6 \pm 11.7$ years. Time interval between symptoms' onset and diagnosis was nearly 10 years. Macroadenoma $(>1 \mathrm{~cm})$ was found in 47 (78.3\%) patients. Diabetes mellitus and hypertension affected 42 (70.0\%) and 37 (61.7\%) individuals, respectively. For disease control, all acromegalics were put on long-acting somatostatin analogue and 21 (35.0\%) of them performed hypophysectomy. In 45 (75.0\%) patients, growth hormone value was dropped to $\leq 2 \mathrm{mg} /$; and in 41 (68.3\%) patients, IGF-1 was normalized for age and sex.

Conclusion The clinco-epidemiological characteristics of acromegaly in Iraq are comparable to that reported in other countries, although there is some delay in time of diagnosis. Associated comorbidities (diabetes and hypertension) affected large number of patients. Good proportion of study sample, nearly two-thirds, showed good metabolic response to treatment.

Keywords acromegaly, growth hormone, insulin-like growth factor-1, pituitary adenoma
\end{abstract}

\section{Introduction}

Acromegaly is a rare chronic condition in adults resulted from continuous over secretion of growth hormone $(\mathrm{GH})$ and hence increased production of insulin-like growth factor-1 (IGF-1). When hypersecretion of GH happens in childhood, the resulted disease is referred to be gigantism rather than acromegaly. In vast majority of cases, the underlying cause of acromegaly has been detected to be micro- or macro-adenoma of pituitary gland.

Acromegalic patients are manifested by unproportioned growth of skeleton, tissues and organs. They may appear with clinical features like skeletal and acral over/abnormal growth, enlargement of soft tissues with frontal bossing, mandibular protrusion, jaw malocclusion, skin thickening, and increase in size of rings and shoes. Other characteristics of this disease are: excessive sweating, paresthesia, goiter, arthritis, kyphoscoliosis, headaches, visual field defects, colon polyps, sleep apnea and day time sleepiness, reproductive disorders and cardiovascular (CV) diseases. ${ }^{2}$ Wide spectrum of manifestations is associated with this disease, ranging from mild to severe clinical phenotypes. Thus, a high index of suspicion is required. ${ }^{3}$

The diagnosis of acromegaly is often delayed for $5-10$ years after time of approximate symptoms onset. ${ }^{4}$ Therefore, patients frequently present with significant comorbidities such as hypertension, diabetes mellitus and sleep apnea. Untreated conditions lead to decrease life expectancy. Causes of death were determined to be mainly due to $\mathrm{CV}$ diseases $(\sim 60 \%)$, respiratory diseases $(25 \%)$ and malignancies $(15 \%)$. With advances in treatment of acromegaly, overall mortality rates have been declined. Although mortalities in patients with acromegaly remain higher than in general population, the increase in deaths is currently less than twofolds, compared with two to threefolds seen in earlier series. ${ }^{5}$

The goals of treatment in acromegaly are symptoms alleviation, tumor size control with preserving pituitary function, biochemical normalization of GH/IGF-1 and reversing the raise in morbidity and mortality associated with this disorder. The current available modalities of treatment involve: surgery, pharmacotherapy and radiotherapy. The decision of required treatment option and therapeutic intervention is based on multiple factors, which need careful weighing and tailoring for each patient in a multidisciplinary frame.

No unified registry has been established in Iraq for acromegalic patients and few studies were performed to evaluate health situation and treatment response of them. Therefore, in order to start such registration, this pilot study has been conducted to evaluate clinico-epidemiological characteristics for a group of Iraqi patients with this disease.

\section{Materials and Methods}

\section{Setting}

This study was conducted on group of acromegalic patients attending National Diabetes Center (NDC) which represent one of the largest specialized centers in Iraq concerned with management of endocrinological diseases, including acromegaly. The case notes and files of randomly selected 60 patients were reviewed by physician during period of October through December 2017. To be included in the study, the 
diagnosis of acromegaly should be confirmed by appropriate laboratory and imagining techniques. The files of only those who regularly attended the center were involved. Ethical approval for conducting the study was obtained from NCD. Each record received a unique study number, so that patients' identity would not be revealed.

\section{Data Collection}

The patient's records were reviewed looking for information concerning demographic factors (age and sex), time of diagnosis, approximate time of symptoms onset; and details of associated comorbidities due to disease or treatment (e.g. hypertension, diabetes mellitus and thyroid disorders). Data and results of treatment options (surgery, pharmacotherapy, and radiotherapy), biochemical control parameters (GH and IGF-1) and reduction in tumor size were also reported.

\section{Outcome Analysis}

Outcome analysis is restricted only to the results of investigations obtained from NCD laboratories. Disease control and biochemical response to management was defined by the criteria of normalized IGF- 1 for age and sex $(Z$-score $\leq 2)$ and a mean $\mathrm{GH}$ value $\leq 2 \mu \mathrm{g} / \mathrm{l}$. Active disease was defined as both an IGF- $1 Z$-score $>2$ and a mean GH value $>2 \mu \mathrm{g} / \mathrm{l}$. Patients with conflicting values of IGF-1 and GH were considered as not controlled. ${ }^{6,7}$

\section{Statistical Analysis}

Data in the records was entered and analyzed using the statistical package for social sciences (SPSS) program, version 20. Descriptive statistics was used; presented as frequencies and proportions (\%), or mean and standard deviation according to the variable type. Results of the statistical analysis of the data are presented in tables and figures with an explanatory paragraph for each, using Microsoft Word Software for windows, version 2013

\section{Results}

As it has been mentioned previously, this study involved 60 patients. They are almost equally distributed among both sexes. Their mean current age is $50.6 \pm 11.7$ years and nearly two-thirds of them lie in fifth and sixth decades of life. By observing age of disease diagnosis and age when patients first notifying symptoms, it can be concluded that time interval between them is nearly 10 years. The radiological imaging revealed that around three quarters of pituitary tumors were macro-adenoma $(>1 \mathrm{~cm})$ and the remaining were classified as micro-adenoma. Table 1 displays these findings.

The registered associated medical disorders among acromegalic patients have been shown in Fig. 1. As it is obvious, diabetes mellitus and hypertension occupy first and second orders respectively. Concerning distribution of thyroid abnormalities among participants; six (10.0\%) have hypothyroidism, five $(8.3 \%)$ have hyperthyroidism, and three $(5.0 \%)$ have clinical goiter without reference to thyroid function. One patient was reported to have aortic incompetence and another was affected by Beckwith-Wiedemann syndrome.

The modalities of treatment and biochemical indicators of disease control are revealed in Table 2. All patients in our study were put on monthly injection of Depot long-acting somatostatin analogue (Sandostatin-LAR) to control disease. Almost

\begin{tabular}{lc}
\hline \multicolumn{2}{l}{ Table 1. Basic characteristics of study sample } \\
\hline Character & Value \\
\hline Number & 60 \\
Current age; $\boldsymbol{n}(\%)$ & $7(11.6 \%)$ \\
$\leq 39$ years & $18(30.0 \%)$ \\
$40-49$ years & $19(31.7 \%)$ \\
$50-59$ years & $16(26.7 \%)$ \\
$\geq 60$ years & $28(46.7 \%)$ \\
Female sex; $\boldsymbol{n}(\%)$ & $46.4 \pm 10.8$ years \\
Age at diagnosis; (mean \pm SD) & $36.7 \pm 10.2$ years \\
Age of symptoms onset; (mean \pm SD) & \\
Type of adenoma; $\boldsymbol{n}(\%)$ & $13(21.7 \%)$ \\
Microadenoma & $47(78.3 \%)$ \\
\hline Macroadenoma &
\end{tabular}

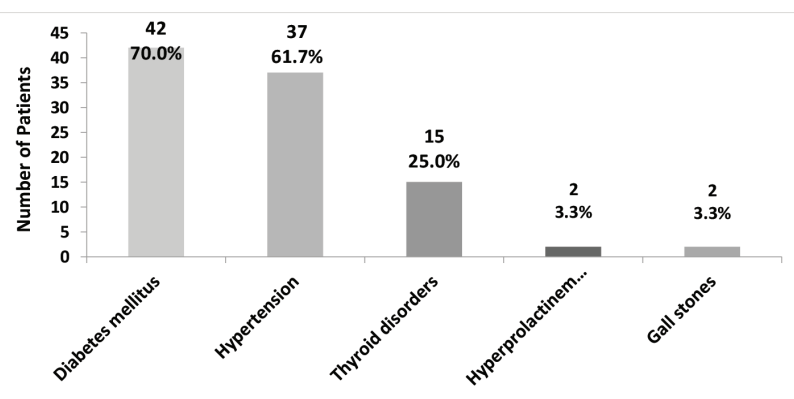

Fig. 1 Associated medical disorders among patients.

\begin{tabular}{lc}
\hline Table 2. Treatment modalities and outcome & \\
\hline Factor & Value, $\mathbf{n}(\%)$ \\
\hline Treatment modalities; $n$ (\%) & \\
Pharmacotherapy alone & $38(63.3)$ \\
Pharmacotherapy + surgery & $21(35.0)$ \\
Pharmacotherapy + surgery + radiotherapy & $1(1.7)$ \\
Biochemical control; $n$ (\%) & \\
Safe GH & $45(75.0)$ \\
Normal IGF-I & $41(68.3)$ \\
Safe GH and Normal IGF-I & $38(63.3)$ \\
Tumor size reduction & $43(71.7)$ \\
\hline
\end{tabular}

one-third of them also performed hypophysectomy and only one was subjected to adjuvant radiotherapy. In three-quarters of patients, mean GH value was dropped to $\leq 2 \mu \mathrm{g} / \mathrm{l}$; and in more than two-thirds, IGF-1 was normalized for age and sex. Consequently, more than $60 \%$ of patients exhibited completed biochemical control as measured by the two biochemical parameters. Decrease in tumor size was observed in more than $70 \%$ of patients. Collectively, $53.3 \%(n=32)$ of patients have improvement in all the above three measures.

\section{Discussion}

Although acromegaly is a rare disease but its effect on life of affected individuals is dramatic and make most of them in 
need for continuous medical care and monitoring. ${ }^{2,5}$ Our study seeks to give a glance on characteristics of disease in Iraq and points of similarities and differences from that reported in studies from other countries.

\section{Demography}

In current study, sex distribution of patients was nearly the same between males and females, which was consistent with that mentioned previously concerning acromegaly affects both sexes equally. ${ }^{89}$ The mean age of patients at diagnosis ( 46.4 years) is comparable to that in other studies which reported to be early- to mid-forties. ${ }^{8-12}$ The delay period of about 10 years between symptoms onset and diagnosis need to be taken into consideration. Although it remained within the limit reported in other places which was 5-10 years, ${ }^{4,13}$ but prompt action must be taken in order to reduce it. Increase awareness of primary health care physicians and other related doctors about collection of symptoms and signs of acromegaly can help to facilitate diagnosis and consequently early management to decrease longterm sequels and comorbidities of this disease.

\section{Type of Adenoma}

The approximate ratio of macro- to micro-adenoma of 3:1 was similar to what found in other countries. The report of Spanish Acromegaly Registry estimated the prevalence of macroadenoma among patients to be $77 \% .{ }^{14}$ Other report from Belgian registry estimated it to be $79 \% .^{7}$ A review article published in the New England Medical Journal found that at the time of diagnosis, more than $75 \%$ of patients with acromegaly have a macro-adenoma, which often expands laterally to the cavernous sinus or dorsally to the suprasellar region. ${ }^{15}$ This higher prevalence of macro-adenoma may reflect delay in diagnosis with subsequent additional symptoms and suffering to patients due to impact of local mass.

\section{Comorbidities}

The prevalence of diabetes mellitus (DM) among acromegalics is known to be much higher than the general population. ${ }^{16}$ In previous studies, overt DM were found in $22-52 \%$ of participants ${ }^{17-19}$; depending on patient's characteristics, clinical setting and treatment type. Nevertheless, the prevalence of DM in this study (70\%) exceeded all that reported before! This result may be attributed to the fact that all our patients were on octreotide hormone drug for a mean period of 4 years since disease diagnosis. Somatostatin analogues (SSAs) including octreotide have been reported to increase risk of secondary diabetes through different mechanisms. Their metabolic effects are the outcome of pros related to reduction in hyperglycemic hormones (growth hormone or adrenocorticotropic hormone) and the cons from decreasing insulin or incretin secretion. ${ }^{20-24}$ Although meta-analysis performed by Mazziotti et al. ${ }^{24}$ concluded that SSAs have a marginal clinical impact on glucose homeostasis in acromegaly, but a pilot study conducted by Parkinson et al. ${ }^{21}$ found that glucose homeostasis tended to deteriorate with octreotide treatment.

The prevalence of hypertension in acromegalic people was ranging between $18 \%$ and $60 \%$ in previous clinical series, and it is almost twice the rate recorded in unaffected people. ${ }^{25-27}$ This increase is thought to be attributed to expansion in plasma volume and sodium retention due to anti-natriuretic action of $\mathrm{GH} .{ }^{25}$ Also, recent studies revealed that the increase in sympathetic tone and/or abnormalities in the circadian rhythm of sympathetic system may have essential role in occurrence of raised blood pressure in acromegalic individuals. ${ }^{26}$

Abnormalities in thyroid gland function are also among registered complications in previous literatures. ${ }^{16}$ In general, there is increase in sensitivity of the thyroid to TSH, modulated by an increase in sympathetic reaction, which leads to normal T4 concentrations despite decreased TSH levels in patients with active acromegaly. ${ }^{28}$ The prevalence of hyperthyroidism has been estimated to be $3.5-26 \%{ }^{29}$ Those with high serum thyroxine level were found previously to have inappropriate normal or elevated level of serum thyrotropin which may indicate cosecretion of thyrotropin by adenoma. ${ }^{30,31}$ Hypothyroidism due to hypopituitarism has been reported in nearly $21-26 \%$ of patients before. This is expected to result from compression of pituitary gland, especially in cases of macro-adenoma, or from surgical treatment of acromegaly. ${ }^{29,32,33}$

\section{Treatment Modalities}

The portion of patients that performed surgical operations (mostly through trans-sphenoidal approach) for tumor was less than that reported in other countries. In Spain, data from acromegaly registry revealed that $81 \%(n=995)$ of patients underwent at least one surgery, most commonly by the trans-sphenoidal route. ${ }^{14}$ In Belgian, $68 \%(n=286)$ of patients underwent 321 surgical procedures, mostly by the transsphenoidal route $(>85 \%){ }^{7}$ No single factor can be set for the low rate of surgeries in our patients. Nevertheless, the nature of thinking of Iraqi patients, who afraid from performing operations in head region, may provide partial explanation for this finding. Additionally, medical therapy has become globally more commonly used as first-line therapy with availability of long acting - somatostatin analogues. On the other hand, the presence of only one person who underwent radiotherapy is expected. Data from Spanish Acromegaly Registry (Registro Espanol de Acromegalia, REA) reported decrease radiotherapy use over time. This is again due to increased usage of long acting - SSAs. ${ }^{14}$

\section{Treatment Outcomes}

This study evaluated the "real-life" effectiveness of medical treatment for acromegaly in Iraq. The outcome of biochemical measures of disease control was comparable (or even better) than that reported in previous studies in developed countries. In AcroBel survey, the overall cure/control rate was $49 \%$ $(n=418) .^{7}$ Data from REA revealed cure in $35 \%$ of 1084 Spanish patients. ${ }^{14}$ In Finnish database, GH and IGF-1 levels were normal in $55 \%(n=314)$ and $55 \%(n=241)$ of patients, respectively. The combination of both measures for evaluation was not conducted, but probably the overall control rate using both of them was also below $50 \% .^{34}$

\section{Conclusion}

In general, the clinico-epidemiological characteristics of acromegaly in Iraq are comparable with that reported in other countries, although there is some delay in time of diagnosis. Associated comorbidities like hypertension and diabetes affected large number of study sample. Good proportion of patients, nearly two-thirds, showed good metabolic response.

The lag period between starting disease and diagnosis should be reduced. This could be done by increase awareness 
of doctors about the disease and conduction of active case detection program. Special care must be given to the management of associated comorbidities as it can affect treatment response, life-expectancy, and quality-of-life of patients. Further studies involving larger sample and multi-center must be done in order to establish unified registry for Iraqi acromegalic patients "Acro-Iraq".

\section{Acknowledgment}

None.

\section{Conflicts of Interest}

None.

\section{References}

1. Banerjee A, Patel K, Wren AM. Acromegaly- clinical manifestations and diagnosis. Pharm J. 2003;13:273-278.

2. Chanson P, Salenave S. Acromegaly. Orphanet J Rare Dis. 2008;3:17.

3. Dineen R, Stewart PM, Sherlock M. Acromegaly. QJM. 2017;110:411-420.

4. Reid TJ, Post KD, Bruce JN, Nabi Kanibir M, Reyes-Vidal CM, Freda PU. Features at diagnosis of 324 patients with acromegaly did not change from 1981 to 2006: acromegaly remains under-recognized and under-diagnosed. Clin Endocrinol (Oxf). 2010;72:203-208.

5. Sherlock M, Ayuk J, Tomlinson JW, Toogood AA, Aragon-Alonso A, Sheppard MC, et al. Mortality in patients with pituitary disease. Endocr Rev. 2010;31:301-342.

6. Alexopoulou O, Bex M, Abs R, T'Sjoen G, Velkeniers B, Maiter D. Divergence between growth hormone and insulin-like growth factor-I concentrations in the follow-up of acromegaly. J Clin Endocrinol Metab. 2008;93:1324-1330.

7. Bex M, Abs R, T'Sjoen G, Mockel J, Velkeniers B, Muermans K, et al. AcroBelthe Belgian registry on acromegaly: a survey of the 'real-life' outcome in 418 acromegalic subjects. Eur J Endocrinol. 2007;157:399-409.

8. Dal J, Feldt-Rasmussen U, Andersen M, Kristensen L $\varnothing$, Laurberg P, Pedersen L, et al. Acromegaly incidence, prevalence, complications, and long-term prognosis: a nationwide cohort study. Eur J Endocrinol. 2016;175:181-190.

9. Burton T, Le Nestour E, Neary M, Ludlam WH. Incidence and prevalence of acromegaly in a large US health plan database. Pituitary. 2016;19: 262-267.

10. Vallette S1, Ezzat S, Chik C, Ur E, Imran SA, Van Uum S, et al. Emerging trends in the diagnosis and treatment of acromegaly in Canada. Clin Endocrinol (Oxf). 2013;79:79-85

11. Lavrentaki A, Paluzzi A, Wass JA, Karavitaki N. Epidemiology of acromegaly: review of population studies. Pituitary. 2017;20:4-9.

12. Cannavò S, Ferraù F, Ragonese $M$, Curtò L, Torre ML, Magistri M, et al. Increased prevalence of acromegaly in a highly polluted area. Eur J Endocrinol. 2010;163:509-513.

13. Zarool-Hassan R, Conaglen HM, Conaglen JV, Elston MS. Symptoms and signs of acromegaly: an ongoing need to raise awareness among healthcare practitioners. J Prim Health Care. 2016;8:157-163.

14. Mestron A, Webb SM, Astorga R, Benito P, Catala M, Gaztambide S, et al. Epidemiology, clinical characteristics, outcome, morbidity and mortality in acromegaly based on the Spanish Acromegaly Registry (Registro Espanol de Acromegalia, REA). Eur J Endocrinol. 2004;151:439-446.

15. Melmed S. Medical progress: acromegaly. N Engl J Med. 2006;355: 2558-2573.

16. Abreu A, Tovar AP, Castellanos R, Valenzuela A, Giraldo CM, Pinedo AC, et al. Challenges in the diagnosis and management of acromegaly: a focus on comorbidities. Pituitary. 2016;19:448-457.

17. Colao A, Auriemma RS, Savastano S, Galdiero M, Grasso LF, Lombardi G, et al. Glucose tolerance and somatostatin analog treatment in acromegaly: a 12-month study. J Clin Endocrinol Metab. 2009;94:2907-2914.

18. Alexopoulou O, Bex M, Kamenicky P, Mvoula AB, Chanson P, Maiter D. Prevalence and risk factors of impaired glucose tolerance and diabetes mellitus at diagnosis of acromegaly: a study in 148 patients. Pituitary. 2014;17:81-89.

19. Dreval AV, Trigolosova IV, Misnikova IV, Kovalyova YA, Tishenina RS, Barsukov IA, et al. Prevalence of diabetes mellitus in patients with acromegaly. Endocr Connect. 2014;3:93-98.

20. Badiu C. Effect of somatostatin analogues on glucose metabolism in acromegaly: friend of foe? AACE Clin Case Rep. 2016;2:e374-e375.

21. Parkinson C, Drake WM, Roberts ME, Meeran K, Besser GM, Trainer PJ. A comparison of the effects of pegvisomant and octreotide on glucose, insulin, gastrin, cholecystokinin, and pancreatic polypeptide responses to oral glucose and a standard mixed meal. J Clin Endocrinol Metab. 2002;87:1797-1804.

22. Ronchi C, Epaminonda P, Cappiello V, Beck-Peccoz P, Arosio M. Effects of two different somatostatin analogs on glucose tolerance in acromegaly. J Endocrinol Invest. 2002;25:502-507.

23. Baldelli R, Battista C, Leonetti F, Ghiggi MR, Ribaudo MC, Paoloni A, et al. Glucose homeostasis in acromegaly: effects of long-acting somatostatin analogues treatment. Clin Endocrinol (Oxf). 2003;59:492-499.

24. Mazziotti G, Floriani I, Bonadonna S, Torri V, Chanson P, Giustina A. Effects of somatostatin analogs on glucose homeostasis: a metaanalysis of acromegaly studies. J Clin Endocrinol Metab. 2009;94:1500-1508.

25. Lombardi G, Galdiero M, Auriemma RS, Pivonello R, Colao A. Acromegaly and the cardiovascular system. Neuroendocrinology. 2006;83:211-217.

26. Bondanelli M, Ambrosio MR, degli Uberti EC. Pathogenesis and prevalence of hypertension in acromegaly. Pituitary. 2001;4:239-249.

27. Vitale G, Pivonello R, Auriemma RS, Guerra E, Milone F, Savastano S, et al. Hypertension in acromegaly and in the normal population: prevalence and determinants. Clin Endocrinol (Oxf). 2005;63:470-476.

28. Roelfsema F, Biermasz NR, Frolich M, Keenan DM, Veldhuis JD, Romijn JA. Diminished and irregular thyrotropin secretion with preserved diurnal rhythm in patients with active acromegaly. J Clin Endocrinol Metab. 2009;94:1945-1950.

29. Dąbrowska AM, Tarach JS, Kurowska M, Nowakowski A. Thyroid diseases in patients with acromegaly. Arch Med Sci. 2014;10:837-845.

30. Beck-Peccoz P, Persani L, Lania A. Thyrotropin-secreting pituitary adenomas. In: De Groot LJ, Chrousos G, Dungan K, et al., eds. Endotext. MDText.com, Inc.; South Dartmouth, MA, 2000. Available from: https://www.ncbi.nlm.nih. gov/books/NBK278978/ [Updated 2015 May 1] [Internet].

31. Socin HV, Chanson P, Delemer B, Tabarin A, Rohmer V, Mockel J, et al. The changing spectrum of TSH-secreting pituitary adenomas: diagnosis and management in 43 patients. Eur J Endocrinol. 2003;148:433-442.

32. Shestakova T, Dreval A, Ilovaiskaja I, Zaharevich E. Study thyroid function in patients with acromegaly. Endocr Abstr. 2012;29:1715.

33. Uchoa HB, Lima GA, Corrêa LL, Vidal AP, Cavallieri SA, Vaisman M, et al. Prevalence of thyroid diseases in patients with acromegaly: experience of a Brazilian center. Arq Bras Endocrinol Metabol. 2013;57:685-690.

34. Kauppinen-Mäkelin R, Sane T, Reunanen A, Välimäki MJ, Niskanen L, Markkanen $\mathrm{H}$, et al. A nationwide survey of mortality in acromegaly. J Clin Endocrinol Metab. 2005;90:4081-4086. 